\title{
QUASI-CONTINUOUS PARTICLE SIZE CHARACTERISATION DURING ACCELERATED STENT RADIAL FATIGUE TEST
}

\author{
Schröder M, Buchholz A, Schmidt W, Brandt C, Schmitz K.-P. \\ Institute for Biomedical Engineering, University of Rostock, Rostock, Germany \\ mark.schroeder@uni-rostock.de
}

\begin{abstract}
Characterisation of particulate matter released during stent radial fatigue testing is of growing importance for stent testing. A method to determine the time course of particulate generation is of notably interest. A new method of quasi-continuous particle counting was developed and validated by measurement of particle recovery. Finally the time-dependent particulate generation of each six DES and BMS was tested. The particle recovery requirements of the FDA were met by the test setup. Stent testing showed a linear increase of particulate matter with increased number of load cycles. The method is suitable to characterize the particle generation during the stent fatigue test.
\end{abstract}

Keywords: Coronary stents, radial fatigue test, particle size characterisation

\section{Introduction}

In general it is assumed that in vasculature released particulate matter is a potential risk factor causing emboli. Considering the risk of high reactivity and passage of blood-tissue boundaries, the necessity of measurement of stent released particulates becomes obvious. Especially coated implant surfaces such as Drug-Eluting-Stents (DES) are seen as sources of particles during delivery, implantation and dynamic loading. [1]

The characterisation of particulate matter generated by the use of stents is defined and standardized by regulations of different institutions such as the ISO [2], ASTM [3] or FDA [4]. Particle measurement of liquid samples collected at the end of fatigue testing does not sufficiently provide data of the time course of particle generation. Furthermore these measurements have to be done with high procedural efforts in a clean room.

For this purpose continuous or quasi-continuous measurements are required.

\section{Methods}

The study consists of two parts. At first the test setup was validated by recovering standard particles after spiking. Afterwards a quasi-continuous particle measurement during a standard fatigue test of 12 stents was conducted.

The recovery study was performed with an extraction setup shown in figure 1 . This setup contained a test chamber with integrated polyurethane (PUR) tubes. The recovery study was performed without stents and electrodynamic vibrations. The recommendations for particle recovery of the FDA are shown in table 1 . Consequently three different particle standards were used $(10 \mu \mathrm{m}, 25 \mu \mathrm{m}$ and $70 \mu \mathrm{m})$. The particle standard solution $(5 \mathrm{ml})$ containing between 3000 and 6000 particles was injected via luer-lock syringe into the open cycle. $50 \mathrm{ml}$ of purified water were led via silicon tubes from the reservoir into the open cycle and collected as sample solution in a closed sample beaker. Several further rinsing $(50 \mathrm{ml})$ followed to ensure the collection of all particles. The whole procedure was repeated at least nine times per particle size. Reference solutions were prepared by adding the same amount of particles to $50 \mathrm{ml}$ pure water without contact to the open cycle. At minimum five reference solutions were generated per particle size.

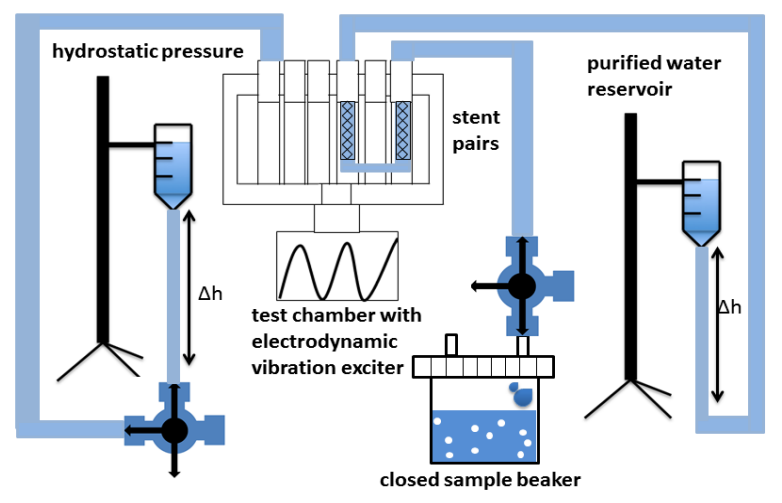

Figure 1: Test setup for the extraction of particle samples

Table 1: Recommended size class and recoveries, FDA [4] and used particle standards

\begin{tabular}{|c|c|c|}
\hline size class & recovery & used particle standard \\
\hline$\geq 10 \mu \mathrm{m}$ & $90 \%$ & $\begin{array}{c}\text { Particle Count Standard } \\
10 \mu \mathrm{m}, \mathrm{BS}-\text { Partikel, }\end{array}$ \\
\hline$\geq 25 \mu \mathrm{m}$ & $90 \%$ & $\begin{array}{c}\text { Particle Size Standard } 25 \mu \mathrm{m} \text {, } \\
\text { Thermo Scientific }\end{array}$ \\
\hline$\geq 50 \mu \mathrm{m}$ & $75 \%$ & $\begin{array}{l}\text { Particle Count Standard } \\
70 \mu \mathrm{m}, \mathrm{BS}-\text { Partikel }\end{array}$ \\
\hline
\end{tabular}

For the quasi-continuous particle measurement during fatigue testing two different stent types were used, see Table 2.

Both types had the same metallic base body but different coatings. Six stents of each type were implanted pairwise into PUR-tubes inside the test chamber. All stents were expanded to $3 \mathrm{~mm}$. Four tubes were kept empty as references. A static load of $150 \mathrm{mmHg}$ caused by the radially stretched PUR-tube and $50 \mathrm{mmHg}$ of hydrostatic pressure were applied to the stents. A dynamic pressure of $\pm 25 \mathrm{mmHg}$ was generated by an electrodynamic vibration exciter $(\mathrm{f}=48 \mathrm{~Hz})$. The tubes were filled with purified water. The pressure and the temperature of $37^{\circ} \mathrm{C}$ in the test chamber were sensor-controlled. 
Table 2: Summary of investigated stents

\begin{tabular}{ccccc}
\hline $\begin{array}{c}\text { stent } \\
\text { type }\end{array}$ & material & $\begin{array}{c}\text { nominal } \\
\text { diameter } \\
\text { [mm] }\end{array}$ & $\begin{array}{c}\text { length } \\
{[\mathbf{m m}]}\end{array}$ & $\begin{array}{c}\text { cover- } \\
\text { ing }\end{array}$ \\
\hline DES & CoCr-alloy & 2.25 & 40 & $\begin{array}{c}\text { polymer } \\
\text { matrix } \\
\text { ceramic }\end{array}$ \\
BMS & $\begin{array}{c}\text { CoCr-alloy } \\
\text { empty }\end{array}$ & 3.0 & 18 & - \\
\hline
\end{tabular}

Particulate samples were extracted directly after implantation. During the whole test of 20 million load cycles (corresponds to half a year of life-time) every 5 million load cycles particulate samples were extracted.

Before measuring the particles the samples were degassed. The samples were homogenised by a magnetic stirrer and measured by a particle counter (HIAC ROYCO model 9703 with the sensor HRLD 400CE) in accordance with USP 788 under a laminar flow box [5].

\section{Results}

For the $10 \mu \mathrm{m}-, 25 \mu \mathrm{m}$ - and $70 \mu \mathrm{m}$ standard particles the spiking and recovery study provided a recovery of $121 \%$, $99 \%$ and $80 \%$, see Figure 2.

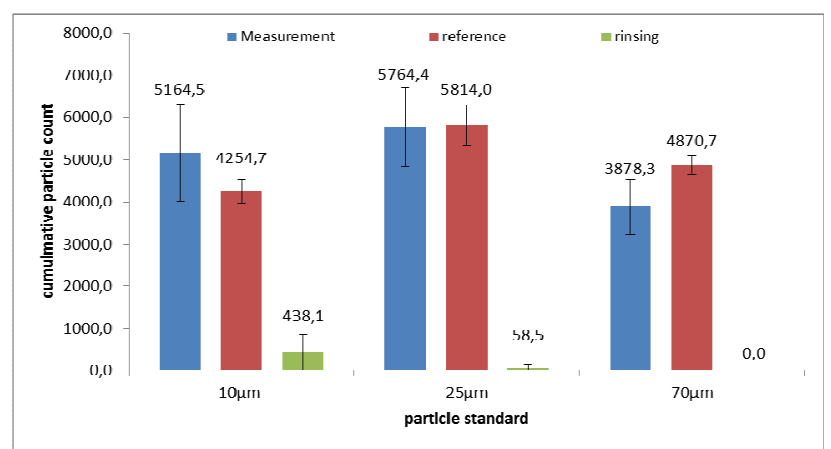

Figure 2: Recoveries of the injected standard particles

The cumulative values of measured particles $\geq 10 \mu \mathrm{m}$ and $\geq 25 \mu \mathrm{m}$ are shown in Figure 3 and Figure 4, whereas the particles values were added up for the load cycles. Both stent types released the largest number of particulate matter during the implantation process. During the fatigue test only a small amount of particles was generated. In general the DES group shows higher particle values than the BMS group. The increase of the particulate matter can be linear approximated. For both stent groups only a negligible number of particles $\geq 50 \mu \mathrm{m}$ were measured (not shown).

\section{Discussion}

For this study a quasi-continuous particle measurement during fatigue testing was developed, validated and tested. During the validation of the setup the standard particles could be recovered and the FDA requirements were fulfilled. The counts of standard particles with a diameter of $10 \mu \mathrm{m}$ exceed the particle counts of the reference because of airbubbles in the sample and statistical differences between the individual measurements.

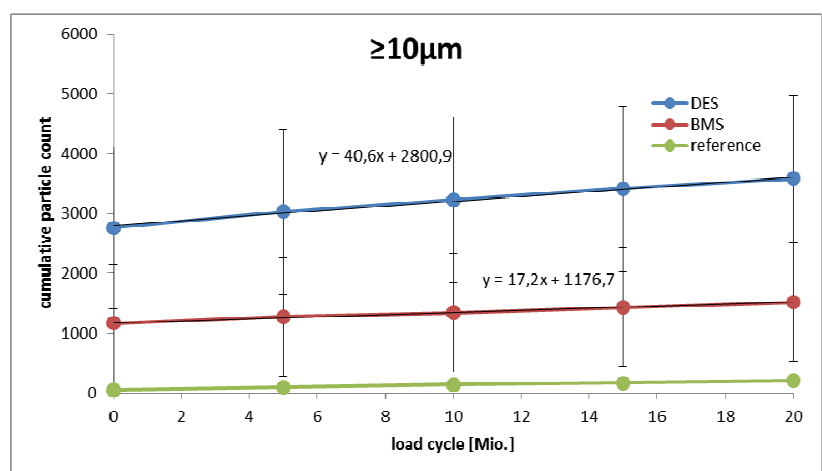

Figure 3: Cumulative particle release for size class $\geq 10 \mu \mathrm{m}$

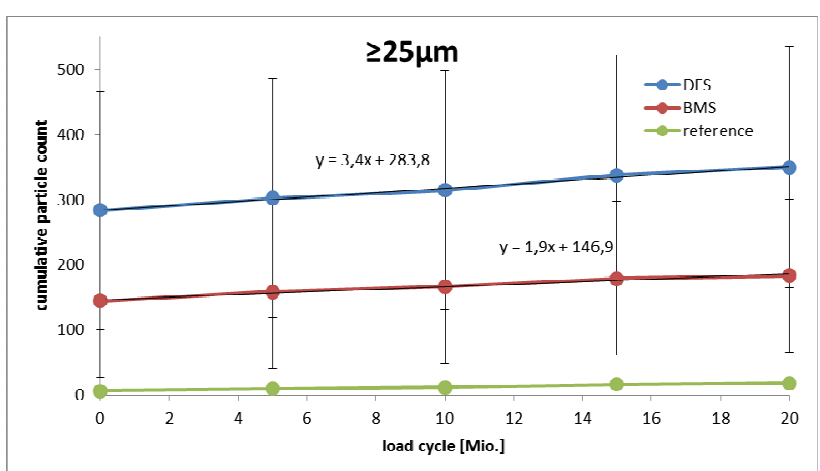

Figure 4: Cumulative particle release for size class $\geq 25 \mu \mathrm{m}$

The results of the quasi-continuous particle measurement during a standard fatigue test show a higher amount of particles for the stents than the references. A direct comparison between both groups of stents is limited by the differing lengths of DES and BMS.

In conclusion, the new quasi-continuous method of particle measurement that provides a course of time and a sampling method with less effort could be proven. A further method of a directly online measurement method is currently investigated.

\section{Acknowledgement}

This project was partially funded by the European Regional Development Fund (ERDF) and the European Social Fund (ESF) within the collaborative research between economy and science of the state MecklenburgVorpommern (V-630-S-090-2010/272).

\section{Bibliography}

[1] W. Schmidt, P. Behrens, M. Teske, C. Schultze, N. Grabow, K. Sternberg, D. Behrend und K.-P. Schmitz, ,Untersuchungmethoden zur Charakterisierung der Schichtintegrität von polymerbeschichteten Drug Eluting Stents, “ Biomedizinische Technik 52 , pp. 333334, 2007.

[2] DIN EN ISO 25539-2_2009 Cardiovascular implants - part 2: vascular stents, 2009.

[3] ASTM F2743-11 Standard Guide for Coating Inspection and Acute Particulate Characterization of Coated Druf-Eluting Vascular Stent Systems (2011)

[4] FDA: Guidance for Industry - Coronary Drug-Eluting Stents Nonclinical and clinical Studies, 2008

[5] USP 788 Particulate matter in injections 